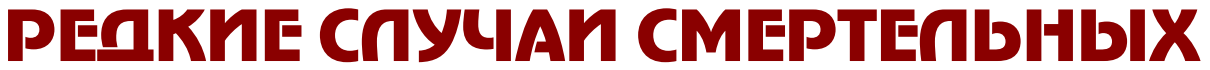 KONOTbIX PAIHEHИЙ
}

\author{
Е. Н. Артемьева ${ }^{1}$, В. В. Фролов ${ }^{1,2}$ \\ ${ }^{1}$ Бюро судебно-медицинской экспертизы Московской области (нач.- д.м.н., проф. В. А. Клевно) \\ 2Кафедра судебной медицины (зав. - д.м.н., проф. В.А. Клевно) ФУв ГБУз МО МОНИКИ \\ им. М.Ф. Владимирского
}

Аннотация: В статье говорится о двух случаях с колотыми ранениями сердца, которые в разные сроки переживания травмы завершились летальным исходом.

Ключевые слова: колющее орудие, колотое ранение

\section{RARE CASES OF FATAL STAB WOUNDS}

\section{E. N. Artemeva, V. V. Frolov}

Abstract: The article refers to two cases with stab wounds of the heart, which at different times experience injuries were fatal.

Keywords: piercing gun, stab wounds

http://dx.doi.org/10.19048/2411-8729-2016-2-1-35-37

В судебно-медицинской практике колотые ранения встречаются гораздо реже других повреждений острыми предметами (колото-резаных, резаных, рубленых). В частности, такой случай был описан в журнале «Судебно-медицинская экспертиза» № 2 за 1982 год [1]. При исследовании трупа мужчины тридцати девяти лет, который неоднократно высказывал мысли о самоубийстве, в левом желудочке сердца была обнаружена игла длиной четыре с половиной сантиметра. Сопоставляя обстоятельства дела с данными исследования трупа, эксперты установили, что игла была введена в межреберный промежуток самим пострадавшим с целью самоубийства.

В нашей практической работе встретились два редких и достаточно интересных случая со смертельными колотыми ранениями сердца.

Труп гражданки К., 1968 г.р. был обнаружен в своем доме на полу в комнате. Согласно представленным материалам проверки, женщина длительное время болела, перенесла несколько оперативных вмешательств на брюшной полости, имела расстройство психики.

Труп женщины на исследование был доставлен одетым в махровый халат и трикотажную футболку. На изнаночной поверхности обеих полочек халата, на уровне реберных дуг было по одному небольшому мазку крови. На футболке спереди обнаружены множественные округлые и овальные, местами сливающиеся пятна крови, размера-

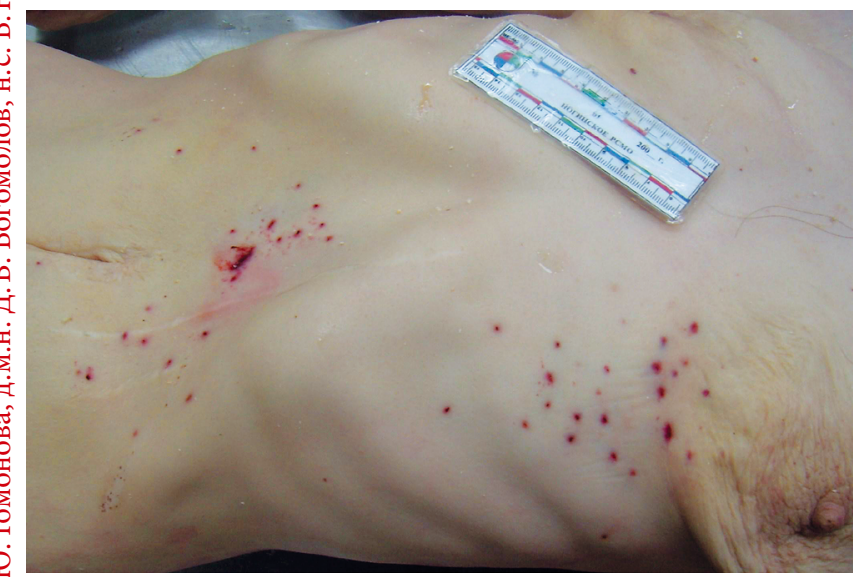

Рис 1. Повреждения на коже грудной клетки и на брюшной стенке ми от точечных до 2,5х1,5см. Каких-либо повреждений на ткани предметов плечевой одежды обнаружено не было.

На теле трупа имелись множественные точечные ранки. На передней поверхности грудной клетки слева между срединно-ключичной и передней подмышечной линиями на уровне 5-7-го межреберий на участке 10x7,5см - двадцать две ранки, на передней брюшной стенке по средней линии и по обе стороны от неё выше пупка девятнадцать ранок (рuc. 1).

Все ранки были покрыты темно-красными кровяными корочками. Обращала на себя внимание большое количество и сгруппированность ранок, а также отсутствие повреждения ткани плечевой одежды в их проекции, что свидетельствовало либо об отсутствии плечевой одежды в момент причинения этих повреждений, либо о смещении предметов одежды в момент, когда эти повреждения причинялись.

В мягких тканях передней поверхности грудной клетки слева и передней брюшной стенки в проекции множественных точечных ран обнаружены прерывистые темно-красные кровоизлияния, среди которых были хорошо различимы многочисленные «дорожки» из кровоизлияний в направлении спереди назад, чуть слева направо (рис. 2). Раневые каналы из-за структуры подкожной жировой клетчатки не прослеживались, но на пристеночной брюшине в проекции группы точечных ран имелись три рядом расположенных точеч-

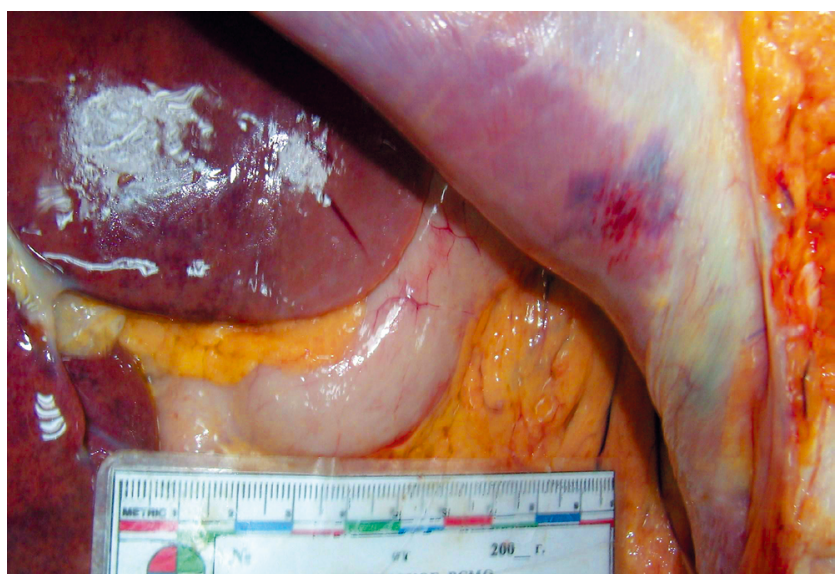

Рис. 2. Кровочзлияние под серозной оболочкой брюшной стенки 
ных повреждения диаметром не более $0,1 \mathrm{~cm}$ и одно линейное повреждение на диафрагмальной поверхности левой доли печени длиной $0,3 \mathrm{~cm}$, глубиной до $0,3 \mathrm{~cm}$. В брюшной полости следов крови не было, в том числе в поддиафрагмальном пространстве по ходу раневого канала в печени.

При вскрытии полости грудной клетки было обнаружено резкое напряжение околосердечной сорочки и через стенку в её полости просвечивалась темнокрасная кровь (рuс. 3). При надавливании на околосердечную сорочку вытекания крови из неё не отмечалось. По ходу одного из раневых каналов от раны на передней брюшной стенке установлено наличие «дорожки» кровоизлияний в месте прикрепления диафрагмы спереди на уровне мечевидного отростка грудины. В жировой клетчатке переднего средостения у верхушки сердца имелось прерывистое кровоизлияние размером $1 \mathrm{x} 0,8 \mathrm{x} 0,5 \mathrm{~cm}$. В полости околосердечной сорочки было около 200 мл жидкой крови и приблизительно такой же объем однородного эластичного блестящего свертка крови. По удалении крови в проекции верхушки сердца на внутренней поверхности сердечной сорочки обнаружены три точечных повреждения диаметром не более $0,1 \mathrm{~cm}$ каждое, расположенные кучно на участке $0,5 \times 0,5$ cм. Соответственно на эпикарде в области верхушки сердца обнаружено Г-образное повреждение со сторонами по 0,3 cм, глубиной около $0,3 \mathrm{~cm}$, в пределах подэпикардиальной жировой клетчатки, с очаговым кровоизлиянием вокруг. В стенке сердца обнаружено полное пересечение ветви левой коронарной артерии, диаметром сечения менее $0,1 \mathrm{~cm}$, что совершенно очевидно и явилось источником кровотечения в полость околосердечной сорочки.

При судебно-гистологическом исследовании кусочков органов и тканей от трупа гр-ки К. установлено наличие лейкоцитарной реакции в области раневых каналов на грудной клетке и передней брюшной стенке, что свидетельствовало о давности переживания повреждений более одного часа.

Сотрудниками полиции было установлено, что при обнаружении трупа родственниками рядом с трупом (под подушкой) были обнаружены несколько игл от одноразовых медицинских шприцов.

Таким образом, точечная форма ран, преобладание длины раневого канала над размерами кожных ран, а также данные материалов расследования свидетельствовали о том, что эти ранения образовались не менее чем от сорока воздействий колющим предметом (предметами) цилиндрической или близкой к таковой формы, диаметром поперечного сечения около $0,1 \mathrm{~cm}$, обладающим острым концом, каковым могла быть игла от медицинского шприца.

Направление раневых каналов спереди назад, чуть снизу-вверх, сгруппированность и множественность ран, локализация повреждений на передней поверхности груди и живота обычно бывает характерно для нанесения их предметом, находившимся в руке у самого потерпевшего, что собственно и позволило нам не исключить такую вероятность причинения обнаруженных повреждений. Смерть гр-ки К. наступила от гемотампонады в результате проникающих колотых ранений с повреждением диафрагмы, сердечной сорочки и наружной оболочки сердца с эпикардиальной артерией. В виду небольшого диаметра просвета поврежденной эпикардиальной артерии, накопление крови в полости околосердечной сорочки происходило сравнительно медленно, и поэтому срок переживаемости повреждений составил более 1 часа.

Второй случай нам представляется также не менее интересным и достаточно необычным.

На судебно-медицинское исследование был доставлен труп гр-ки Т., 59 лет. Труп был доставлен на исследование одетым в халат, с направлением участкового полицейского, в котором не было никакой информации, кроме того, что труп женщины был обнаружен в квартире, в кровати, без видимых признаков насильственной смерти.

Действительно, при исследовании трупа женщины не было установлено каких-либо наружных телесных повреждений. Однако при внутреннем исследовании было обнаружено следующее: в полости сердечной сорочки имелись рыхлые белесоватые спайки, с трудом разделяющиеся тупым путем. В толще околосердечной сорочки, в проекции верхушки сердца имелся участок обызвествления размерами $3 \times 4$ см, с бугристой поверхностью толщиной до 0,7 см. Над поверхностью обызвествления выступал фрагмент инородного тела черного цвета. В толще этот участок обызвествления экспертом был обнаружен заостренный металлический стержень длиной 3,5 cм, диаметром поперечного сечения до 1,5 мм, с острым концом и с утолщением (головкой) на другом конце. Поверхность стержня покрыта слоем желто-коричневой ржавчины. На участке обызвествления также обнаружено два похожих стержня длиной по 1 см цилиндрической формы диаметром по 1 мм, с ржавой поверхностью (рис. 4).

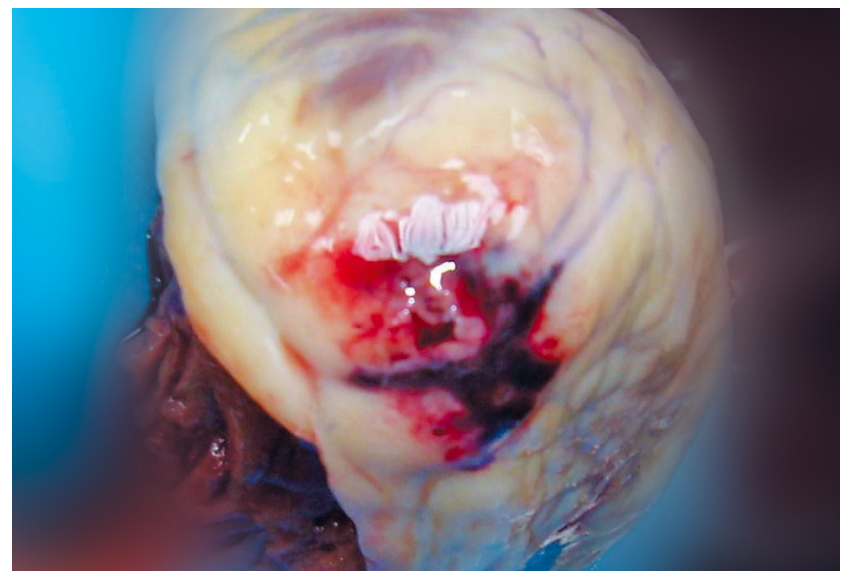

Рис. 3.. Повреждениена верхушке сердиас кровоизлиянием

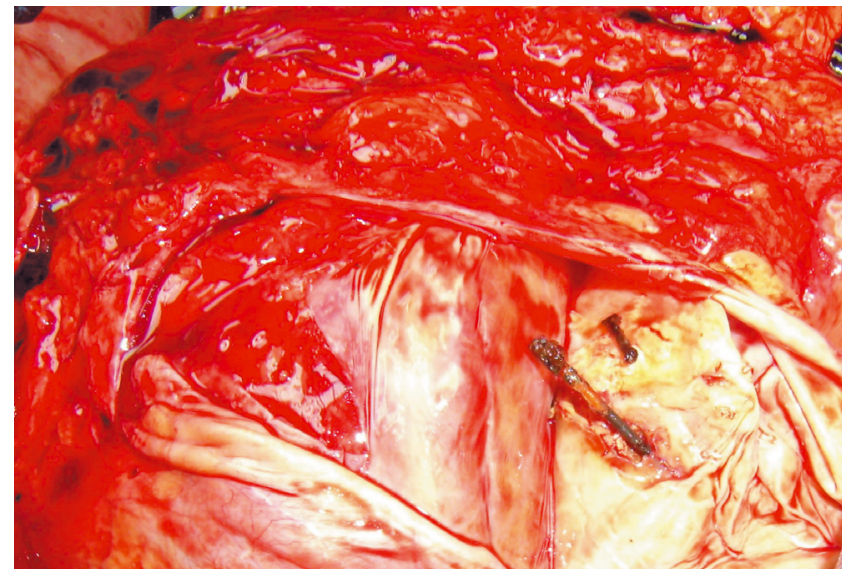

Рис. 4. Инородное тело (металлический стержень) в толще околосердечние сорочки 


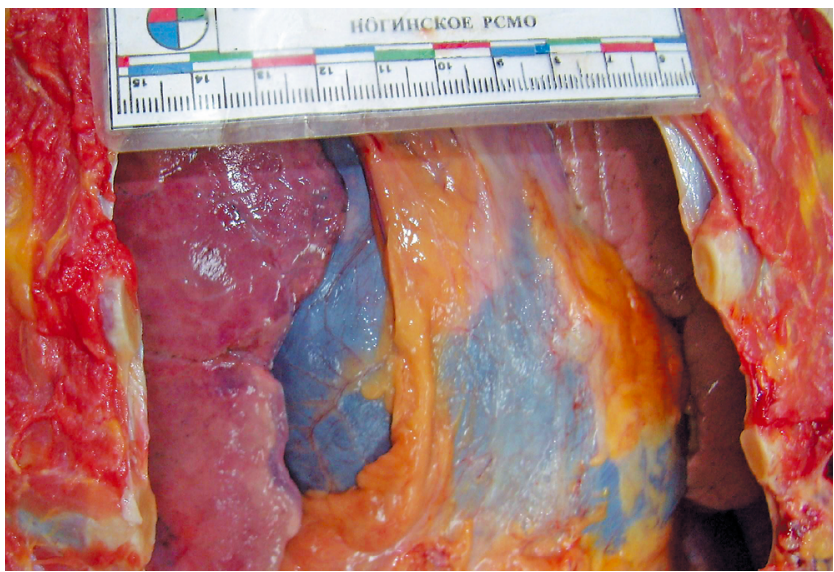

Рис. 5. Просвечивается кровоизлияние в полости околосердечной сумки

Сердце размерами $11 \times 10 x 4,5$ см, массой 486 гр., в полостях его содержалась жидкая кровь и эластичные однородные темно-красные свертки. На наружной оболочке сердца каких-либо рубцов и свежих повреждений обнаружено не было, в том числе и в проекции расположения инородных тел. Полости сердца были слегка расширены, клапаны утолщены, белесоватые, у основания с выраженным кальцинозом, без повреждений.

Под наружной оболочкой сердца кровоизлияний не было. Сосуды сердца на разрезах зияли, стенки их были равномерно утолщенными, с множественными желтоватыми, бугристыми местами кальцинированными бляшками, суживающими просветы сосудов местами на 1/2. Мышца сердца была дрябловатая на ощупь, на разрезах бледно-коричневая, с множественными белесоватыми прожилками, с участками неравномерного кровенаполнения. Толщина стенки левого желудочка $1,4 \mathrm{~cm}$, правого 0,4 cм.

Интима аорты шероховатая, желтоватая, с множественными бугристыми, белесоватыми бляшками. По- вторно прицельно была осмотрена кожа на грудной клетке спереди и на её боковых поверхностях, при этом каких-либо рубцов на ней не было обнаружено.

Материал был направлен на судебно-гистологическое исследование. При гистологическом исследовании были установлены следующие изменения в кусочках сердца: «Эпикард отечный с полнокровными сосудами. Вены под эпикардом резко расширены, полнокровны. Миокардиоциты неравномерно гипертрофированы, среди них группы миоцитов фрагментированы. Межмышечная, периваскулярная строма отечная, с очагово-диффузной лимфо-макрофагальной инфильтрацией. В строме мелкие очаги сетчатого склероза. В толще кусочков сердца сосуды неравномерно кровенаполнены, отдельные из них с гранулостазами. По ходу них разрастание соединительной ткани. К эндокарду прилежат свертки крови.

Был выставлен судебно-гистологический диагноз: «Межуточный миокардит. Неравномерное полнокровие вен, отек стромы миокарда. Неравномерно выраженная гипертрофия миокардиоцитов. Мелкоочаговый стромогенный, периваскулярный кардиосклероз». Это позволило нам прийти к выводу, что женщина умерла от сердечной недостаточности при развившемся хроническом межуточном миокардите, причиной которого, наиболее вероятно стало ранее причиненное ранение околосердечной сумки и, очевидно, стенки сердца (рuс. 5).

Эти случаи представляют очевидный интерес, прежде всего, по причине их возникновения. А именно, эти ранения были причинены предметами, которые в обыденной жизни не представляют какой-либо серьезной опасности, и их трудно было бы представить себе, как предметы, которыми можно нанести смертельное ранение.

\section{$\checkmark$ ЛИТЕРАТУРА}

1. Клевно, В.А. Попытка самоубийства путем введения швейной иглы в сердце / В.А. Клевно // Судебномед. экспертиза. 1982.- Т. 25, № 2.- С. 52.

\section{Для корреспонденции:}

АРТЕМЬЕВА Елена Николаевна - врач - судебно-медицинский эксперт государственного бюджетного учреждения здравоохранения Московской области «Бюро судебно-медицинской экспертизы» •142450, г. Старая Купавна, ул. Матросова, д. 15 • artemeva@sudmedmo.ru

ФРОЛОВ Василий Васильевич - заведующий танатологическим отделом государственного бюджетного учреждения здравоохранения Московской области «Бюро судебно-медицинской экспертизы» (ГБУЗ МО «Бюро СМЭ») по экспертной работе, кандидат медицинских наук, врач - судебно-медицинский эксперт высшей квалификационной категории, ассистент кафедры судебной медицины ФУВ ГБУЗ МО МОНИКИ им. М.Ф. Владимирского • (ГБУЗ МО «Бюро СМЭ») 111401, г. Москва, ул. 1-я Владимирская, д. 33, корп. 1; (ГБУЗ МО «МОНИКИ им. М.Ф. Владимирского») 129110, г. Москва, ул. Щепкина 61/2, корпус 1, «Административный» подъезд • frolov@ sudmedmo.ru 